\title{
TEOR DE COMPOSTOS FENÓLICOS LIVRES E LIGADOS AO LONGO DO DESENVOLVIMENTO DE GRÃOS DE TRIGO DE DIFERENTES CULTIVARES
}

Fabiana Ramos Nascimento, Tatiana de Souza Medina, Millena Cristina Barros Santos, Mariana Simões Larraz Ferreira (mariana.ferreira@ unirio.br)

Laboratório de Bioativos, Núcleo de Bioquímica Nutricional, Programa de Pós-Graduação em Alimentos e Nutrição (PPGAN), Universidade Federal do Estado do Rio de Janeiro (UNIRIO), Brasil.

O trigo ocupa o primeiro lugar em volume e produção mundial de cereais. Alimentos à base de trigo também apresentam níveis significativos de compostos bioativos e estudos epidemiológicos apontam que o consumo de cereais auxilia na prevenção de doenças e promoção da saúde. Nos cereais, ácidos fenólicos representam a classe mais abundante de compostos fenólicos, existindo na forma livre e ligada, sendo estes últimos os mais abundantes. O objetivo desse estudo foi avaliar pela primeira vez o teor de fenólicos livres, ligados e totais em grãos de trigo (T. aestivum) brasileiro em diferentes estágios de maturação. Foram avaliadas sete cultivares (cv.) de trigo nos estados leitoso, pastoso, maturidade fisiológica e maduro. A partir de grãos liofilizados e moídos, os compostos fenólicos livres foram extraídos em etanol (80\%), após homogeneização e centrifugação. A partir do pellet, os compostos ligados foram extraídos após hidrólise alcalina, seguida de ácida. Os extratos foram filtrados, evaporados e ressuspendidos. Os teores de compostos fenólicos foram determinados em triplicata em leitora de microplacas pelo método de Folin-Ciocalteau e os resultados expressos em equivalente de ácido gálico (EAG). Os resultados foram avaliados por ANOVA com pós-teste de Tukey $(\mathrm{p}=0,05)$ pelo software GrandPad Prism( $\odot$ 6.0. Os teores de compostos fenólicos totais, livres e ligados decaíram significativamente ao longo da maturação do grão. O maior teor de compostos fenólicos totais (livres e ligados) foi observado nos grãos leitosos da cv. ORS 1401 (391,97 mg EAG/100g), enquanto que o menor teor foi encontrado em grãos maduros da cv. Jadeíte (148,91 mg EAG/100g). O teor de fenólicos totais nos estágios de maturação leitoso para pastoso variou de 7\% (Campeiro) a 21\% (ORS 1401), com exceção das cv. Marfim e ORS 1402, onde o teor manteve-se constante. A variação do teor de fenólicos totais entre a maturidade fisiológica e o grão maduro não foi significativa. No entanto, em algumas amostras, este teor foi ligeiramente maior em grãos maduros do que na maturidade fisiológica, porém, a diferença não excedeu $8 \%$. Esta diferença deve-se principalmente ao teor de compostos fenólicos livres que se mostrou em média 30\% superior nas cv. ORS 1401, ORS 1402, ORS 25, Jadeíte e Ametista no estado maduro. Os maiores teores de compostos fenólicos livres e ligados foram encontrados, respectivamente, na ORS 25 (155,03 mg EAG/100g) e na ORS 1401 (255,01 mg EAG/100g), ambos no estágio mais imaturo leitoso. Foi possível observar diferença no teor de compostos fenólicos em relação aos estágios de maturação dos grãos, tipos de extração e cultivares. Conclui-se que os grãos de trigo das diversas cv. brasileiras analisadas apresentam diferentes teores de compostos fenólicos e podem ser selecionadas de acordo com o teor e perfil de compostos bioativos. Para melhor caracterizar os compostos fenólicos das variedades de trigo brasileiro, análises por UPLC-MS estão sendo conduzidas. Palavras chaves: extração de fenólicos, Folin-Ciocalteau, compostos bioativos. 